\title{
Color stability, surface roughness and microhardness of composites submitted to mouthrinsing action
}

\author{
Marília Salomão Campos Cabrini FESTUCCIA ${ }^{1}$, Lucas da Fonseca Roberti GARCIA ${ }^{2}$, Diogo Rodrigues CRUVINEL ${ }^{3}$, \\ Fernanda de Carvalho Panzeri PIRES-DE-SOUZA ${ }^{4}$
}

\begin{abstract}
1- DDS, Department of Dental Materials and Prosthodontics, Ribeirão Preto School of Dentistry, University of São Paulo, Ribeirão Preto, SP, Brazil. 2- DDS, MS, PhD, Department of Dental Materials and Prosthodontics, Ribeirão Preto School of Dentistry, University of São Paulo, Ribeirão Preto, SP, Brazil. 3- DDS, MS, Department of Dental Materials and Prosthodontics, Ribeirão Preto School of Dentistry, University of São Paulo, Ribeirão Preto, SP, Brazil. 4- DDS, MS, PhD, Department of Dental Materials and Prosthodontics, Ribeirão Preto School of Dentistry, University of São Paulo, Ribeirão Preto, SP, Brazil.
\end{abstract}

Corresponding address: Profa. Dra. Fernanda de Carvalho Panzeri Pires-de-Souza - Faculdade de Odontologia de Ribeirão Preto - USP - Departamento de Materiais Dentários e Prótese - Avenida do Café, s/n - Bairro Monte Alegre - 14040-904 - Ribeirão Preto - SP - Brazil - Phone: +55-16-3602-3973 - Fax: +55-016-3633-0999 - e-mail: ferpanzeri@usp.br

Received: June 02, 2010 - Modification: June 09, 2011 - Accepted: July 08, 2011

\section{ABSTRACT}

\begin{abstract}
bjective: The purpose of this study was to evaluate the effect of mouth rinse solutions on color stability, surface roughness and microhardness of two composite resins. Material and Methods: Fifty test specimens of each composite (Filtek Z250 and Z350; 3M ESPE) were made using a teflon matrix $(12 \times 2 \mathrm{~mm})$. Color, surface roughness and Knoop microhardness baseline measurements of each specimen were made and specimens $(n=10)$ were immersed in 5 mouth rinse solutions: G1: distilled water (control), G2: Plax Classic, G3: Plax alcohol-free; G4: Periogard, and G5: Listerine. Final measurements of color, roughness and microhardness were performed and the results submitted to statistical analysis (2-way ANOVA, Bonferroni's test; $p<0.05)$. Results: The most significant color change was observed for Z250 when immersed in Listerine $(p<0.05)$. Z350 showed greater color change when immersed in Plax alcohol-free $(p<0.05)$, but with no significant difference for Listerine $(p>0.05)$. With regard to roughness, both composites showed significant changes when immersed in Listerine in comparison with Plax alcohol-free $(p<0.05)$. Microhardness of Z350 was shown to be significantly changed when the composite was immersed in Plax alcohol-free $(p<0.05)$. Conclusion: Composite changes depended on the material itself rather than the mouth rinse solution used.
\end{abstract}

Key words: Composite resins. Oral hygiene. Dental materials. Physical properties.

\section{INTRODUCTION}

Color and surface roughness are very important properties in aesthetics, characterizing a smile ${ }^{21}$. Since the introduction of composites in 1960, efforts have been made to increase the longevity of composite restorations. Although some progress has been made, optical properties in this type of materials need to be improved 5 .

The color change of composites is multifactorial, being associated with intrinsic discoloration and extrinsic staining of the material. Intrinsic factors involve changes in the chemical stability of resin matrix and matrix/particles interface, and extrinsic factors are related to absorption of staining solutions from exogenous sources related to hygiene habits, food, and smoking ${ }^{8}$.

Composite structure and the characteristics of the inorganic fillers have a direct impact on composite resin surface smoothness ${ }^{26}$ and susceptibility to extrinsic staining ${ }^{24}$. Several studies have shown that composite resins are susceptible to color alteration when exposed to staining solutions, especially red wine, coffee, cola, tea and whisky ${ }^{2,9}$. Furthermore, this property depends on both water absorption of the composite and its hydrophilic resin matrix to allow permeation of staining agents, thus resulting in greater color changes ${ }^{2}$.

Today, the number of people using mouth rinse 
solutions for anti-microbial control has increased not only because of professional recommendations, but also due to the capacity of such materials to provide cooling sensation and to reduce halitosis ${ }^{7}$. Mouth rinse solutions have various components such as detergents, emulsifiers, organic acids, dyes and alcohol. It is known that composite resins exposed to ethanol exhibit lower microhardness values compared to non-exposed materials ${ }^{23}$. According to Sarret, et al.22 (2000), alcohol acts as a plasticizer of the polymeric matrix, making the material more ductile. In addition, ethanol can reduce bonding between resin matrix and inorganic fillers, which might decrease erosion resistance and cause staining of resin matrix ${ }^{23}$.

Thus, the purpose of this study was to evaluate the effect of mouth rinse solutions on color stability, surface roughness and microhardness of composite resins. The null hypothesis stated that mouth rinse solutions would not promote changes in the properties of the studied composites.

\section{MATERIAL AND METHODS}

\section{Samples preparation}

Two direct composite resins (shade A3) currently indicated for esthetic anterior and posterior restorations were used in the present study. Information regarding composite type, composition and manufacturer is given in Figure 1.

Fifty cylindrical test specimens (12 mm diameter $\times 2 \mathrm{~mm}$ thick) of each composite were made using a Teflon matrix. Each material was inserted into the matrix in 2 increments and light-activated by a LED device (FLASHlite 1401, Discus Dental, Culver City, CA, USA, light intensity $\geq 1100 \mathrm{~mW} /$ $\mathrm{cm}^{2}$, wavelength in the range between 460 and 480 $\mathrm{nm}$ ), for 20 seconds, according to manufacturer's recommendations. The specimens were polished with 320, 600, 1200 and 2000-grit sandpapers. The thickness of every test specimen was checked with a digital caliper (Digimess, São Paulo, SP, Brazil). Next, the test specimens were randomly separated into 5 groups $(n=10)$ according to the mouth rinse solution in which they had been immersed (Figure
2): Group 1 - distilled water (control); Group 2 Plax classic; Group 3 - Plax alcohol-free; Group 4 - Periogard; and Group 5 - Listerine Cool Mint.

To simulate the use of mouth rinse solutions once a day during a period of 1 year, the test specimens were submitted to 12 cycles of 1 -min immersion, then washed in running water and immersed in distilled water for $29 \mathrm{~min}$ at $37^{\circ} \mathrm{C}$, during 30 days, totaling 360 cycles $^{11}$.

\section{Color stability}

Before immersion, color reading of the test specimens was performed according to the CIE (Commission Internationale de l'Eclairage) L*a*b* system, against a white background (Standard for $45 / 0^{\circ}$; Gardner Laboratory Inc., Bethesda, $M D, U S A)$ in a reflection spectrophotometer (PCB 6807, BYK Gardner, Geretsried, Germany). This equipment is specific for color reading and has 30 LED lamps with 10 different colors arranged in a circle, which directs a light bundle at $45^{\circ}$ with the material surface. This light bundle is reflected $0^{\circ}$ back to the equipment, which captures and records the $L^{*}, a^{*}$ and $b^{*}$ values of each specimen. The $L^{*}$ axes refers to the lightness coordinate and its value ranges from zero (black) to 100 (white). The axis a* and $b^{*}$ are chromaticity coordinates in the redgreen axis and the yellow-blue axis, respectively. Positive a* values indicate a shift to red and negative values indicate a shift to green. Similarly, positive $b^{*}$ values indicate the yellow color range and negative values indicate the blue color range.

After immersion in mouth rinse solutions, specimens color was measured by the spectrophotometer, as previously described. Based on the $L^{*}, a *, b^{*}$ values, color variation $(\Delta E)$ was determined using the following equation:

$$
\Delta \mathrm{E}=\left[\left(\Delta \mathrm{L}^{*}\right)^{2}+\left(\Delta \mathrm{a}^{*}\right)^{2}+\left(\Delta \mathrm{b}^{*}\right)^{2}\right]^{1 / 2}
$$

Values of $\Delta \mathrm{E} \geq 3.3$ were considered clinically unacceptable 20 .

Surface roughness and Knoop microhardness Surface roughness $\left(R_{a}\right)$ and Knoop microhardness

\begin{tabular}{|c|c|c|c|c|c|}
\hline \multirow{2}{*}{$\begin{array}{c}\text { Commercial } \\
\text { name }\end{array}$} & \multirow[t]{2}{*}{ Type } & \multirow[t]{2}{*}{ Monomers } & \multicolumn{2}{|c|}{ Load particles } & \multirow[t]{2}{*}{ Manufacturer } \\
\hline & & & Size $(\mu \mathrm{m})$ & Volume $\%$ & \\
\hline Filtek Z250 & Microhybrid & $\begin{array}{c}\text { Bis-GMA, UDMA, } \\
\text { Bis-EMA }\end{array}$ & Zirconia/Silica $0.6 \mu \mathrm{m}$ & $60 \%$ & $\begin{array}{c}\text { 3M ESPE Dental Products, } \\
\text { St Paul, MN, USA }\end{array}$ \\
\hline Filtek Z350 & Nanoparticulate & $\begin{array}{c}\text { Bis-GMA, Bis- } \\
\text { EMA, UDMA and } \\
\text { TEGDMA }\end{array}$ & $\begin{array}{l}\text { Zirconia/Silica } 5-20 \mathrm{~nm} \\
\text { with clusters of } 0.6-1.4 \\
\mu \mathrm{m}\end{array}$ & $59.5 \%$ & $\begin{array}{c}\text { 3M ESPE Dental Products, } \\
\text { St Paul, MN, USA }\end{array}$ \\
\hline
\end{tabular}

Bis-GMA: bisphenol A diglycidyl ether dimethacrylate; Bis-EMA: Ethoxylated bisphenol A dimethacrylate, TEGDMA:Triethylene glycol dimethacrylate; UDMA: urethane dimethacrylate

Figure 1- Tested composites 
of the test specimens were performed before and after mouth rinse solution immersion. Surface roughness was measured with a Rugosimeter (Mitutoyo SJ-201P, Mitutoyo, Tokyo, Japan), cutoff $-0.25 \mathrm{~mm}, \mathrm{~L}_{\mathrm{c}}$ parameter - 1.25 , speed -0.1 $\mathrm{mm} / \mathrm{s}$. The rugosimeter needle (10 $\mu \mathrm{m}$ diameter) was positioned over each test specimen, performing three readings in different locations of the sample surface, after which, the mean roughness of the test specimens were obtained. Surface roughness changes were calculated by the differences between mean values obtained before and after immersion.

The Knoop microhardness of the test specimens was measured (Shimadzu device, HMV Shimadzu, Kyoto, Japan) in three different points, with a 10 $\mathrm{N} / 15 \mathrm{~s}$ load. After three readings, the microhardness mean values of the test specimens were obtained. For Knoop microhardness calculation, the baseline mean values were subtracted from those obtained after immersion.

\section{Statistical analysis}

For each property, data obtained were subjected to two-way ANOVA and the measurements were compared by the Bonferroni's test. All statistical testing was performed at a pre-set alpha of 0.05 .

\section{RESULTS}

\section{Color stability}

The mean values and standard deviations for color stability $(\Delta E)$ changes are presented in Table 1. None of the studied composites exhibited color change with values above the clinically acceptable limit $(\Delta E \geq 3.3)^{20}$. With regard to $Z 250$, comparison of the effects of different mouth rinse solutions revealed a small color change for specimens immersed in Listerine, with statistically significant difference compared with the other mouth rinse solutions $(p<0.05)$. When immersed in Plax Classic solution, this composite exhibited an intermediate

\begin{tabular}{|c|c|c|c|}
\hline Commercial name & Composition & pH & Manufacturer \\
\hline Plax Classic & $\begin{array}{c}\text { Triclosan, Gantrez, Sodium lauryl sulphate, } \\
\text { Glycerin and Propylene, Sodium fluoride (225 } \\
\text { ppm fluoride), Sodium methyl taurate, Disodium } \\
\text { phosphate, Sodium saccharine, red dye, ethylic } \\
\text { alcohol (6\%) and water }\end{array}$ & 5.8 & $\begin{array}{c}\text { Colgate Palmolive Ind. e Com. } \\
\text { Ltda., São Bernardo do } \\
\text { Campo, SP, Brazil }\end{array}$ \\
\hline Plax Alcohol-free & $\begin{array}{c}\text { Cetyl Pyridinium Chloride (CPC) 0.05\% } \\
225 \text { ppm fluoride, Gantrez, Sodium lauryl sulphate, } \\
\text { Glycerin and Propylene, Sodium methyl taurate, } \\
\text { phosphoric acid, Disodium phosphate, Sodium } \\
\text { saccharine and water }\end{array}$ & 4.96 & $\begin{array}{c}\text { Colgate Palmolive Ind. e Com. } \\
\text { Ltda., São Bernardo do } \\
\text { Campo, SP, Brazil }\end{array}$ \\
\hline Periogard & $\begin{array}{c}0.12 \% \text { gluconate (or digluconate formulation } \\
\text { with chlorhexidine-free concentration (0.067\%), } \\
\text { water, glycerin, ethanol, polysorbate 20, aromatic } \\
\text { composition with predominant flavor of mint, } \\
\text { sodium saccharine, FD\&C blue dye \#1 }\end{array}$ & $5.0-7.0$ & $\begin{array}{c}\text { Colgate Palmolive Ind. e Com. } \\
\text { Ltda., São Bernardo do } \\
\text { Campo, SP, Brazil }\end{array}$ \\
\hline Listerine & $\begin{array}{c}\text { Thymol, eucalyptol, methyl salicylate, menthol, } \\
\text { excipients: purified water, sorbitol solution, alcohol } \\
(30 \%), \text { poloxamer 407, benzoic acid, mint essence, } \\
\text { sodium saccharine, sodium benzoate, green dye } \\
\text { \#3 }\end{array}$ & 3.7 & Laboratório Pfizer Ltda., São \\
Paulo, SP, Brazil
\end{tabular}

Figure 2- Tested mouth rinses

Table 1- Means (standard deviations) for $\Delta E$ values (2-way ANOVA, Bonferroni's test; $p<0.05$ )

\begin{tabular}{ccc}
\hline & Z250 & Z350 \\
\hline Control & $1.52(0.37)^{\mathrm{a}, \mathrm{A}}$ & $0.96(0.24)^{\mathrm{b}, \mathrm{AB}}$ \\
Listerine & $0.99(0.29)^{\mathrm{a}, \mathrm{B}}$ & $1.25(0.24)^{\mathrm{a}, \mathrm{AC}}$ \\
\hline Plax Classic & $1.32(0.46)^{\mathrm{a}, \mathrm{AB}}$ & $0.64(0.23)^{\mathrm{b}, \mathrm{B}}$ \\
Plax alchohol-free & $1.42(0.45)^{\mathrm{a}, \mathrm{A}}$ & $1.46(0.30)^{\mathrm{a}, \mathrm{C}}$ \\
\hline Periogard & $1.40(0.71)^{\mathrm{a}, \mathrm{A}}$ & $0.93(0.16)^{\mathrm{b}, \mathrm{AB}}$ \\
\hline
\end{tabular}

Different lowercase letters in lines and uppercase letters in columns indicate statistically significant difference. 
Table 2- Means (standard deviations) for $R_{a}(\%)$ values (2-way ANOVA, Bonferroni's test; $p<0.05$ )

\begin{tabular}{ccc}
\hline & Z250 & Z350 \\
\hline Control & $44.94(0.34)^{\mathrm{a}, \mathrm{A}}$ & $27.60(0.28)^{\mathrm{a}, \mathrm{A}}$ \\
Listerine & $78.46(0.56)^{\mathrm{a}, \mathrm{AB}}$ & $61.99(0.53)^{\mathrm{a}, \mathrm{AB}}$ \\
Plax Classic & $38.28(0.18)^{\mathrm{a}, \mathrm{A}}$ & $13.36(0.18)^{\mathrm{a}, \mathrm{A}}$ \\
Plax alcohol-free & $-4.22(0.20)^{\mathrm{a}, \mathrm{AC}}$ & $-10.76(0.27)^{\mathrm{a}, \mathrm{AC}}$ \\
\hline Periogard & $64.43(0.46)^{\mathrm{a}, \mathrm{AB}}$ & $58.22(0.34)^{\mathrm{a}, \mathrm{AB}}$ \\
\hline
\end{tabular}

Different lowercase letters in lines and uppercase letters in columns indicate statistically significant difference.

Table 3- Means (standard deviations) for Knoop microhardness (\%) values (2-way ANOVA, Bonferroni's test; $p<0.05)$

\begin{tabular}{ccc}
\hline & Z250 & Z350 \\
\hline Control & $7.30(0.17)^{\mathrm{a}, \mathrm{A}}$ & $22.28(0.18)^{\mathrm{a}, \mathrm{A}}$ \\
Listerine & $-14.88(0.10)^{\mathrm{a}, \mathrm{A}}$ & $1.20(0.27)^{\mathrm{a}, \mathrm{A}}$ \\
\hline Plax Classic & $-6.98(0.08)^{\mathrm{a}, \mathrm{A}}$ & $15.83(0.40)^{\mathrm{a}, \mathrm{A}}$ \\
Plax alcohol-free & $-5.03(0.23)^{\mathrm{a}, \mathrm{A}}$ & $-25.73(0.19)^{\mathrm{a}, \mathrm{B}}$ \\
\hline Periogard & $-0.24(0.18)^{\mathrm{a}, \mathrm{A}}$ & $14.80(0.24)^{\mathrm{a}, \mathrm{A}}$ \\
\hline
\end{tabular}

Different lowercase letters in lines and uppercase letters in columns indicate statistically significant difference.

$\Delta \mathrm{E}$ value without statistically significant difference compared to other mouth rinse solutions ( $p>0.05)$. With regard to $\mathrm{Z350}$, the highest $\Delta \mathrm{E}$ change was observed for Plax alcohol-free solution, with statistically significant difference compared with the other solutions ( $p>0.05)$, except for Listerine. Comparing the composites to each other, it was observed statistically significant difference $(p<0.05)$ for the test specimens immersed in distilled water (control), with both Plax Classic and Periogard solutions allowing smaller color changes for Z350.

\section{Surface roughness}

The mean values and standard deviations for surface roughness $\left(R_{a}\right)$ changes are presented in Table 2. For both composites, the greatest change in $R_{a}$ occurred when the samples were immersed in Listerine solution, with statistically significant difference compared with Plax alcoholfree $(p<0.05)$. When compared to each other, Z250 and Z350, showed no statistically significant difference $(p>0.05)$ regarding any studied mouth rinse solution.

\section{Knoop microhardness}

The mean values and standard deviations for Knoop microhardness changes are presented in Table 3. When compared to each other, Z250 and Z350 showed no statistically significant difference $(p>0.05)$ regarding any studied mouth rinse solution. Immersion of Z350 in Plax alcoholfree solution resulted in greater decrease of microhardness values, with statistically significant difference in relation to the other mouth rinse solutions $(p<0.05)$.

\section{DISCUSSION}

The variability in our results was consistent with other studies, which showed that several factors, including composite resin type, mouth rinse solution and immersion cycle, had a significant influence on color stability, surface roughness and microhardness of composites ${ }^{28}$. Therefore, the null hypothesis could not be accepted.

Color stability can be evaluated both visually and by specific instruments ${ }^{5,8,11}$. The methodology used in the present study is according to previous studies that used spectrophotometry and the CIE L*a*b* coordinates system ${ }^{5,11}$. The CIE L*a*b* system was chosen to evaluate color variation $(\Delta \mathrm{E})$ because it is appropriate for small color changes determination and have advantages such as repeatability, sensitivity and objectivity ${ }^{11}$.

Several authors have reported that $\Delta \mathrm{E}$ values ranging from 1 to 3 are perceptible to the naked eye $^{18}$ and $\Delta \mathrm{E}$ values greater than 3.3 are clinically unacceptable ${ }^{20}$. Considering these concepts; the composite resins tested in the present study demonstrated acceptable color stability when stored in the different types of mouth rinse solutions (Table 1).

The affinity of the resin matrix for stains is modulated by its conversion degree and by some physical properties, such as water sorption ${ }^{2,6}$. Water sorption of composite resins depends on the resinous matrix composition. It has been reported that water uptake in Bis-GMA based composite 
resins increased from 3 to $6 \%$, as the proportion of TEGDMA increased from 0 to $1 \%{ }^{13}$. UDMA seems to be more stain resistant than Bis-GMA ${ }^{15}$, and under normal curing conditions, UDMA based composite resins presented lower water sorption and higher color stability than other dimethacrylates in their resin matrix ${ }^{15,20}$, which could be observed in the present study.

Moreover, it is important that the composite resin presents uniform filler particle distribution in the polymer network to minimize the formation of filler-rich and filler-depleted areas within the composites. This is especially important regarding the performance of composites in aqueous environments, such as mouth rinse solutions, since voids or nonbonding spaces at the filler/ matrix interface may increase the water sorption of composites ${ }^{25}$.

Nanocomposites correspond to a class of new materials with nanoscale inorganic filler particles dispersed within the resinous matrix ${ }^{27}$. In comparison with microhybrid composites, these materials have been reported to have improved properties, such as, elasticity modulus, mechanical strength and color stability. Furthermore, these improvements are achieved at low concentrations of the inorganic filler particles. This fact contrasts strongly with conventional filled composites, which generally require high loadings within the range of $60 \%{ }^{11,19}$. This is an important factor in aesthetic maintenance of non-particulate composites, since filler particles are responsible for spreading the light, which in turn, provides the opacity of the restorative resin materials. The larger the filler particle size the greater the light spread, and consequently, the greater the opacity ${ }^{16}$. The opacity of composites increases as the difference between the refraction indexes of resinous matrix and filler particles also increases ${ }^{16}$. In addition, the smaller the filler particle, the smaller the amount of water absorbed by the polymer network, which results in lower degradation of the interface matrix/particle, and consequently, lower color change ${ }^{10}$. The $Z 250$ contains filler particles with average size of $0.6 \mu \mathrm{m}$, while Z350 contains filler particles ranging from 5 to $20 \mathrm{~nm}$, which could explain the greater color stability for Z35029. Also, according to Kawaguchi, et al. ${ }^{14}$ (1994), microhybrid composites present a lower coefficient of light transmission due to the various sizes of their particles, which contributed to the higher values of $\Delta \mathrm{E}$ for $\mathrm{Z} 250$.

According to Villalta, et al. ${ }^{30}$ (2006), the low $\mathrm{pH}$ and alcohol concentration of solutions affect the surface roughness of composite resins and cause staining. Nevertheless, the composite Z350 presented statistically significant difference regarding color stability, surface roughness and microhardness values when the composite was immersed in the alcohol-free mouth rinse solution (Plax alcohol-free), thus contradicting the results of a previous study ${ }^{30}$. However, Miranda, et al. ${ }^{17}$ (2011) demonstrated that despite the absence of alcohol, Plax alcohol-free has phosphoric acid in its composition, which might alter the polymer matrix of composites by catalysis of the ester groups present in the dimethacrylate monomers. The hydrolysis of the ester groups forms alcohol and carboxylic acid molecules, which accelerate polymer network degradation by the decrease of $\mathrm{pH}$ inside the composite matrix ${ }^{10,17}$. The degradation of the polymer network leads to a phenomenon called "plasticization", which decreases microhardness values in composites ${ }^{10}$.

According to the methodology used in the present study, the negative values regarding microhardness represent a smoothening of the resin matrix, and positive values, hardening. Despite the great decrease in the composite microhardness $(-25.73)$, the surface roughness improved when compared to the pre-immersion values, except when the composite was immersed in the Plax alcohol-free solution. The same result was observed for Z250, since a significant change in surface roughness was found after immersion into the same mouth rinse solution. It is worth emphasizing, however, that there exists a critical value regarding surface roughness change $\left(R_{a} \geq 0.2\right.$ $\mu \mathrm{m})$. According to Bollen, et al. ${ }^{3}$ (1997), a greater biofilm retention allows an increase in recurrent caries. Another critical value for $R_{a}$ is $0.3 \mu \mathrm{m}$, which can be detected when the patient's lips or tongue enters in contact with the restorative material, causing discomfort ${ }^{3}$. None of the studied composites showed values for surface roughness change above the critical limits, irrespective of the type of mouth rinse solution used.

Asmussen $^{1}$ (1984) reported that mouth rinse solutions with high alcohol content might soften the composite resin, especially Bis-GMA-based composites. However, Gürgan, et al. ${ }^{12}$ (1997) showed that regardless of the alcohol concentration, both alcohol-containing and alcohol-free mouth rinse solutions could affect the properties of composite resins. Immersed of Z350 in Listerine, the mouth rinse solution with the highest alcohol concentration $(30 \%)$, resulted in decrease in microhardness values, though with no significant difference from the other mouth rinse solutions. As for Z250, the results were the opposite; there was an increase in the microhardness values when immersed in Listerine and a decrease when immersed in Plax alcohol-free solution, with statistically significant difference. These results suggest that changes in the microhardness of composites do not depend on mouth rinse's ethanol concentration ${ }^{12}$.

The same finding could be observed regarding 
to color stability. Z350 showed significant changes when immersed in Listerine and Plax alcohol-free solutions, both having entirely different concentrations of ethanol ${ }^{12}$. However, this fact could be explained, once again, by the presence of phosphoric acid in Plax alcohol-free composition. Studies have reported the release of by-products from polymer network degradation, such as methacrylic acid, formaldehyde and specific methacrylate molecules, which are capable of promoting color change in composites ${ }^{4,10,17}$.

On the other hand, Z250 had greater color change when immersed in Listerine compared to the other solutions, unlike Celik, et al. ${ }^{4}$ (2008), who found no color change in the composites immersed in the same mouth rinse solution, despite the high ethanol concentration.

Clinically, the effect of mouth rinse solutions on restorative materials can be modified by several factors that were not replicated in this in vitro study. Among these factors, saliva could dilute or buffer $\mathrm{pH}$ of mouth rinse solutions, thus reducing the effect of resinous matrix plasticization ${ }^{10}$ and forming a pellicle that could have a protective effect on the composite surface, thus, decreasing material staining ${ }^{4}$. Based on such factors, further in vivo studies are needed to determine the effects of mouth rinse solutions on these properties of composites.

\section{CONCLUSIONS}

The results of the present study allow us to conclude that the changes observed in the composites depended on the material itself rather than the mouth rinse solution used.

\section{REFERENCES}

1- Asmussen E. Softening of BISGMA-based polymers by ethanol and by organic acids of plaque. Scand J Dent Res. 1984;92:257-61. 2- Bagheri R, Burrow MF, Tyas M. Influence of food-simulating solutions and surface finish on susceptibility to staining of aesthetic restorative materials. J Dent. 2005;33:389-98.

3- Bollen CM, Lambrechts $P$, Quirynen M. Comparison of surface roughness of oral hard materials to the threshold surface roughness for bacterial plaque retention: a review of the literature. Dent Mater. 1997;13:258-69.

4- Celik C, Yuzugullu B, Erkut S, Yamanel K. Effects of mouth rinses on color stability of resin composites. Eur ] Dent. 2008;2:247-53. 5- Cruvinel DR, Garcia LF, Consani S, Pires-de-Souza FCP. Composites associated with pulp-protection material: colorstability analysis after accelerated artificial aging. Eur J Dent. 2010;4:6-11.

6- De Gee AJ, ten Harkel-Hagenaar E, Davidson CL. Color dye for identification of incompletely cured composite resins. J Prosthet Dent. 1984;52:626-31.

7- DeVore LR. Antimicrobial mouthrinses: impact on dental hygiene. J Am Dent Assoc. 1994;2:23S-28S.

8- Dietschi D, Campanile G, Holz J, Meyer JM. Comparison of the color stability of ten new-generation composites: an in vitro study. Dent Mater. 1994;10:353-62.
9- Ertaş E, Güler AU, Yücel AC, Köprülü H, Güler E. Color stability of resin composites after immersion in different drinks. Dent Mater J. 2006;25:371-6.

10- Ferracane JL. Hygroscopic and hydrolytic effects in dental polymer networks. Dent Mater. 2006;22:211-22.

11- Gürdal P, Akdeniz BG, Hakan Sen B. The effects of mouthrinses on microhardness and colour stability of aesthetic restorative materials. J Oral Rehabil. 2002;29:895-901.

12- Gürgan S, Önen A, Köprülü $H$. In vitro effects of alcoholcontaining and alcohol-free mouthrinses on microhardness of some restorative materials. J Oral Rehabil. 1997;24:244-6.

13- Kalachandra S, Turner DT. Water sorption of polymethacrylate networks: bis-GMA/TEGDM copolymers. J Biomed Mater Res. 1987;21:329-38.

14- Kawaguchi M, Fukushima T, Miyazaki T. The relationship between cure depth and transmission coefficient of visible-lightactivated resin composites. J Dent Res. 1994;73:516-21.

15- Khokhar ZA, Razzoog ME, Yaman P. Color stability of restorative resins. Quintessence Int. 1991;22:733-7.

16- Lee YK. Influence of filler on the difference between the transmitted and reflected colors of experimental resin composites. Dent Mater. 2008;24:1243-7.

17- Miranda DA, Bertoldo CE, Aguiar FH, Lima DA, Lovadino JR. Effects of mouthwashes on Knoop hardness and surface roughness of dental composites after different immersion times. Braz Oral Res. 2011;25:168-73.

18- Noie F, O'Keefe KL, Powers JM. Color stability of resin cements after accelerated aging. Int J Prosthodont. 1995;8:51-5.

19- Rong MZ, Zhang MQ, Pan SL, Friedrich K. Interfacial effects in polypropylene-silica nanocomposites. J Appl Polym Sci. 2004; $92: 1771-81$.

20- Ruyter IE, Nilner K, Moller B. Color stability of dental composite resin materials for crown and bridge veneers. Dent Mater. 1987;3:246-51.

21- Samra AP, Pereira SK, Delgado LC, Borges CP. Color stability evaluation of aesthetic restorative materials. Braz Oral Res. 2008;22:205-10.

22- Sarret DC, Coletti DP, Peluso AR. The effect of alcoholic beverages on composite wear. Dent Mater. 2000;16:62-7.

23- Schneider LF, Moraes RR, Cavalcante LM, Sinhoreti MA, Correr-Sobrinho L, Consani S. Cross-link density evaluation through softening tests: effect of ethanol concentration. Dent Mater. 2008;24:199-203.

24- Shintani H, Satou J, Satou N, Hayashihara H, Inoue T. Effects of various methods on staining and accumulation of Streptococcus mutans HS-6 on composite resins. Dent Mater. 1985;1:225-7. 25- Skrtic D, Antonucci JM, McDonough WG, Liu DW. Effect of chemical structure and composition of the resin phase on mechanical strength and vinyl conversion of amorphous calcium phosphate-based composites. J Biomed Mater Res A. 2004,68:76372.

26- Tjan AH, Chan CA. The polishability of posterior composites. J Prosthet Dent. 1989;61:138-46.

27- Ure D, Harris J. Nanotechnology in dentistry: reduction to practice. Dent Update. 2003;30:10-5.

28- Venturini D, Cenci MS, Demarco FF, Camacho GB, Powers JM. Effect of polishing techniques and time on surface roughness, hardness and microleakage of resin composite restorations. Oper Dent. 2006;31:11-7.

29- Vichi A, Ferrari M, Davidson CL. Color and opacity variations in three different resin-based composite products after water aging. Dent Mater. 2004;20:530-4.

30- Villalta P, Lu H, Okte Z, Garcia-Godoy F, Powers JM. Effects of staining and bleaching on color change of dental composite resins. J Prosthet Dent. 2006;95:137-42. 